\title{
VIAJE CON UN MAPA EN BLANCO ENSAYO SOBRE EL LUGAR DE LA NOVELA
}

\author{
Juan Gabriel Vásquez
}

Hace cinco años, como he contado ya en alguna parte, el escritor Santiago Gamboa y yo tuvimos el placer de conversar en público con Carlos Fuentes, el autor de varias de las páginas que han dado forma a nuestra vida de lectores. Hacia el final de la conversación, Gamboa le preguntó a Fuentes cuáles eran las cinco novelas que todo el mundo debía leer. Fuentes fue estirando lentamente sus largos dedos de pitonisa, esos dedos ya torcidos por la edad y las teclas duras, mientras decía con voz de mantra:

—El Quijote, el Quijote, el Quijote, el Quijote y el Quijote.

Virginia Woolf dice que leer Hamlet todos los años y escribir nuestras impresiones es como escribir nuestra autobiografía, porque las grandes obras cambian con el tiempo, pero además son como espejos que nos muestran también cómo vamos cambiando. Frente a Don Quijote, los años y las lecturas me han traído la convicción escandalosa de que la novela no es, como lo creí alguna vez, el mejor instrumento jamás inventado por el ser humano para explorarse a sí mismo, sino que las cosas son mucho más simples: el ser humano es el mejor invento de la novela. En otras palabras (nueva proposición escandalosa), la novela nos ha construido como somos. Utilizo la palabra invención, y no olvido lo que tanto le gustaba a ese gran heredero de Cervantes que fue Henry Fielding: en su origen latino, inventio significa descubrimiento. Inventar, lo que (me dicen) hacemos los novelistas, es descubrir: descubrir lo humano, des-cubrir zonas ocultas de lo humano, ir a esos lugares de nuestra condición y nuestra conciencia adonde no se podría ir de otra forma y luego regresar para contarnos lo que hay en ellos: he aquí la virtud de la novela, lo que la hace central e irremplazable.

¿Pero qué significa eso exactamente? ¿Cuáles son esos lugares a los que sólo la novela puede llegar? Imaginemos el mundo en el que Cervantes escribió Don Quijote. Se han propuesto 
muchas fechas para el momento en que Cervantes comenzó a escribir la novela, pero lo más probable es que aquello haya ocurrido en el último lustro del siglo XVI. En los cien años anteriores, el universo se ha transformado tanto que se ha vuelto irreconocible: hemos descubierto que nuestra tierra es mucho más extensa — pues hay un continente nuevo y lleno de misterios del otro lado del mar-, pero además sabemos que el planeta que pisamos gira alrededor del sol, y no al revés. Los descubrimientos de Colón y Copérnico han echado abajo varias de nuestras certidumbres, varias de las verdades incontrovertibles sobre las cuales hemos construido hasta ahora nuestra noción de nosotros mismos. En medio de un mundo monolítico, de verdades absolutas y de represión de las ideas nuevas, varios descubrimientos comienzan a hacer mella en ese sistema de valores y jerarquías. Cervantes es parte de ese conjunto de revoluciones. Don Quijote, igual que Colón y que Copérnico, descubre un territorio nuevo. (Un día de 1600, en Italia, Giordano Bruno muere en la hoguera de la Inquisición por, entre otras cosas, creer en la posibilidad de otros sistemas solares; siempre me ha gustado fijarme en el hecho de que más o menos al mismo tiempo, en España, Cervantes tiene también su fe puesta en un territorio al que nadie se ha asomado.) Es difícil ponerle un nombre a ese territorio, porque la novedad de Cervantes es múltiple; pero cuando he hablado de que Don Quijote nos inventa como somos, me refería a dos transformaciones que la novela ejerce sobre el mundo, dos complejísimos cambios de visiones y actitudes que resulta tosco y grosero resumir en apenas un par de palabras. $Y$ sin embargo se me ocurren dos palabras que son como las puntas del iceberg, pues apenas sugieren un volumen mucho mayor ( $y$ al escogerlas confieso algo de atajo vergonzante pero también de inevitable necesidad). Dos palabras, he dicho: humanismo e ironía.

La relación que nos pide Cervantes establecer con sus personajes es profundamente revolucionaria en la ficción en prosa: ni en los libros de caballerías, ni en las leyendas artúricas que nos cuenta Thomas Malory, ni en las ficciones de la antigüedad —Apuleyo o Heliodoro, por poner dos ejemplos-, nos habían pedido que nos involucráramos con tanta intensidad con las emociones de hombres y mujeres que no eran ni dioses, ni nobles, ni héroes, ni criaturas de la fantasía como aquel pobre Lucio convertido en asno. El invento de Cervantes nos sugiere que el hombre común y corriente, el que vemos todos los días, el compañero de nuestra cotidianidad, tiene una profundidad y un interés que no es visible. El único antecedente real que se me ocurre es el Lazarillo de Tormes, cuyo retrato de una vida y de una sociedad lo llevó a los índices de libros prohibidos y, nuevamente, a las hogueras de la Inquisición. De hecho, es posible ir más allá: sin ese librito anónimo, Cervantes, que lo leyó bien, no hubiera sabido llegar al Quijote. 
Pero lo importante es que el Quijote toma las intuiciones del autor anónimo del Lazarillo y las convierte en una visión, en una manera de estar en el mundo: la manera de la empatía.

En Los testamentos traicionados Kundera dice algo que siempre me ha gustado:

La sociedad occidental se suele presentar como la sociedad de los derechos del hombre, pero antes de que un hombre tuviera derechos, se tenía que constituir como individuo, considerarse individuo y ser considerado como individuo; y eso no habría podido pasar sin la larga experiencia de las artes europeas, y en particular el arte de la novela, que enseña al lector a sentir curiosidad por los otros y a tratar de comprender verdades distintas de la suya propia.

Así es: la novela crea nuestra noción de individuo. Al enseñarnos a sentir curiosidad por los otros, al adiestrarnos en el intento por comprender verdades distintas de la nuestra, la novela abre un espacio nuevo en nuestras vidas individuales, pero también en nuestras vidas de ciudadanos. La gran tragedia griega nos hace testigos de una situación y busca, a través de la acción visible de los personajes, que sintamos el terror y la lástima de los que hablaba Aristóteles. Pero nunca dejamos de ver la situación desde fuera: de ser, como digo, testigos de lo que le pasa a otro. La revolución de la novela, que ve a los personajes desde dentro, está en ese hecho que hoy nos parece tan simple: durante la lectura, somos nosotros y a la vez ellos, vemos a Raskolnikov o a Madame Bovary y al mismo tiempo somos Raskolnikov o Madame Bovary. El resultado es que nos exploramos a nosotros mismos como nunca antes lo habíamos hecho: vemos el mundo desde una perspectiva familiar y al mismo tiempo completamente impredecible y sorprendente. La novela nos cuenta quiénes somos.

Las novelas son sondas morales. Las enviamos a lugares oscuros o desconocidos; las iluminaciones que nos traen nos permiten un renovado aprendizaje del mundo, de sus complejidades y las nuestras, de la ambigüedad, multiplicidad e inestabilidad de nuestro carácter. Ford Madox Ford dijo lo mismo de otro modo en un libro maravilloso'. Para Ford, la novela comienza a descubrirse —es decir, a reconocer sus talentos, sus virtudes y su campo de acción — con Diderot y enseguida con Stendhal.

En ese punto fue repentinamente obvio que la Novela como tal era capaz se ser considerada como medio para una discusión profundamente seria y de muchos lados, y por lo tanto, como medio para una investigación profundamente seria del caso humano.

\footnotetext{
${ }^{1}$ The English Novel. From the Earliest Days to the Death of Joseph Conrad. Ford, según su propia nota de autor, lo escribió en julio y agosto de 1927 y en tres lugares: en Nueva York, a bordo del SS. Patria y en el puerto de Marsella y sus alrededores. Es un librito breve, pero capaz de despertar cariño allí donde otros despiertan sólo admiración.
} 
Notemos que el adjetivo serio se repite, y además lo acompaña un adverbio: profundamente. En las décadas que median entre Diderot y Stendhal — para ser precisos: entre Jacques le fataliste y Le rouge et le noir-, la novela todavía está jugándose su reputación, su lugar entre las artes; todavía es tensa su relación con sus propios orígenes cómicos (Rabelais, el Quijote, Tristram Shandy). Y sin embargo, Henry Fielding había declarado, en una página de su Tom Jones, que «el alimento que proponemos no es otro que la naturaleza humana». Le tomó a la novela varias décadas Ilegar al fondo de la propuesta de Fielding, reconocer que no era nada distinto lo que había venido haciendo durante más de siglo y medio y, finalmente, entrever en esa propuesta una suerte de identidad.

Pero ahora quisiera concentrarme en los términos de Ford.

Primero: la novela es una discusión de muchos lados. Ignoro si Ford tenía en mente a Cervantes cuando escribió estas líneas, pero este rasgo fundamental de la novela, que consiste en ser un terreno donde varias ideas o valores opuestos entre sí son igualmente válidos, es una de las grandes invenciones (nuevamente: los grandes descubrimientos) del Quijote. En esas breves palabras de Ford están contenida toda una manera de ver el mundo que es esencialmente novelística, pues la discusión de muchos lados implica la esforzada neutralidad del autor, que no absuelve ni condena a sus personajes: el lector se adentra en un territorio donde, como dice Kundera, el juicio moral queda suspendido, y lo que nos mueve es el afán de entender. De hecho, en esa discusión de muchos lados es probable que las ideas o las opiniones o las convicciones o los prejuicios del autor queden fuertemente en entredicho. En enero de 1872, Ana Stepanovna Pirogov, una amiga de Tolstoi que se había visto envuelta en una relación adúltera, se arrojó a las vías del tren después de que su amante la dejara. Tolstoi, impresionado por el suceso, comenzó a escribir Ana Karenina con una idea fija en la cabeza: el suicidio era su castigo por el adulterio. Pero a medida que fue avanzando en la novela, no pudo evitar que la figura de la adúltera fuera creciendo en complejidad y en profundidad, mientras que la del marido -el representante del orden, de la moralidad, de los valores cristianos- se fue apocando. Al final, la grandeza moral de Ana contrasta con la mezquina mediocridad de Karenin: el novelista que había en Tolstoi se impuso al moralista. Las novelas ven más claro, o más lejos, que sus autores.

Segundo: la novela es una investigación y su objeto es el caso humano. The human case: me gustan estas palabras. Lo humano como problema, como enigma, como misterio; lo humano como zona ignota, inexplorada, desconocida. Joseph Conrad (cuyas novelas, dicho sea de paso, dieron forma a la idea que Ford tenía del género) cuenta en sus memorias un episodio de su 
niñez, cuando contaba unos nueve años. Mirando un mapa de África, puso el dedo en el espacio en blanco que representaba el misterio de ese continente, y se dijo:

«Cuando crezca, iré allí».

Lo hizo, por supuesto. Un cuarto de siglo después, viajó a la región de Stanley Falls, remontó el río Congo y recaudó experiencias, memorias y un diario; y nueve años después del viaje aparecerían en Inglaterra las tres entregas de una novela corta de título tremebundo, El corazón de las tinieblas, la historia de un hombre que remonta un río, penetra un territorio desconocido para rescatar a un hombre, y acaba haciendo descubrimientos (sobre ese hombre, pero también sobre sí mismo) aterradores y a la vez necesarios. Esto es lo que hace toda novela valiosa: observar un mapa, el mapa de un territorio que nunca ha sido explorado, y dirigirse a él para llenar esos espacios en blanco con los resultados de su exploración. El mapa en blanco es el de la condición humana, ese continente misterioso que la novela ha ido descubriendo, iluminando, con cada una de sus conquistas, y nosotros, los lectores de novelas, vamos a bordo de esa nave. Hay provincias enteras de nuestro mapa que ya no están en blanco porque por ellas han pasado las grandes novelas. El pasado es un territorio menos desconocido desde que Marcel metió una magdalena en una taza de té; ciertos rincones de nuestra condición, con frecuencia los más terribles, son menos amenazantes para quien ha estado en el subsuelo de Dostoievski o ha compartido manteles con el Gran Inquisidor. Con El proceso descubrimos una realidad pesadillesca (o debería decir: una pesadilla demasiado real) que nunca habíamos visitado, y lo mismo ocurrió con Cien años de soledad: fueron novelas que abrieron una frontera y así enriquecieron o ensancharon el mundo conocido. ( $\mathrm{Y}$ ahora, cuando alguien exclama que una situación es kafkiana, cuando alguien dice de algo que «eso es puro realismo mágico», no es necesario haber leído a Kafka o a García Márquez para saber a qué se refiere.) Sin esas novelas, aquellos lugares permanecerían ocultos; no los sabríamos ver; o, habiéndolos encontrado por una casualidad afortunada, no sabríamos reconocerlos. Y seríamos más pobres por ello.

De nuevo Conrad: «Sólo en la imaginación de los hombres encuentra la verdad una existencia efectiva e innegable. La imaginación, no la invención, es la suprema dueña del arte así como de la vida». Conrad, por supuesto, no usa la palabra invención como nos la ha legado Fielding y como la he venido usando aquí. Lo que parece decir es que el novelista no es tan sólo un constructor de fábulas; lo que le da autoridad al arte es aquello que llamamos imaginación. Y yo añadiré un adjetivo: moral. La imaginación moral es esa posibilidad de entrar en la situación vital, emocional, existencial y psicológica de otro. La imaginación moral es la interpretación, 
como si se tratara de una partitura, de las vidas ajenas, la lectura que hacemos de sus misterios y sus secretos: de sus dimensiones invisibles. La imaginación moral es la capacidad de abandonar las abstracciones con que solemos arropar una decisión —la patria, la iglesia o la secta, el partido, la revolución, el pueblo, el progreso- para explorar la experiencia concreta de otro ser humano, las dichas o el sufrimiento concretos de otro ser humano. La imaginación literaria nos obliga a pasar de lo abstracto a lo concreto, y quizás por eso es un gran antídoto contra los fanatismos y los fundamentalismos. Los fanatismos - ya se trate de regímenes, iglesias o individuos- son enemigos de la novela; me temo que la antipatía es mutua. La compulsión de ver detrás de la máscara, la cacería obsesiva de las vidas ocultas, es un impulso prosaico, pero maravillosamente humano. Es acaso la fascinación por lo que los demás ocultan lo que predispone a cualquiera para una vida de lector, o si la lectura de cierta tradición de ficciones lo convierte a uno en ese mirón, ese voyeur, ese indiscreto. Pero sé que los lectores de novelas tarde o temprano se contaminan de esas indiscreciones que, en los mejores casos, llegan a convertirse en aquella curiosidad de que hablaba Kundera, ese esfuerzo por comprender vidas distintas de las nuestras. «La novela», dice Elizabeth Costello, la escritora inventada por John Coetzee, «es el intento por comprender el destino humano caso por caso».

Los pensadores de la Ilustración, que habían comenzado a estudiar hasta el último rincón de la naturaleza a través de las nuevas ciencias —la botánica, la zoología, la química, la física-, propusieron en algún momento una idea osada: si las ciencias podían dar todas las respuestas sobre la naturaleza, pensaron, de seguro podría crearse una ciencia de lo humano capaz de darlas todas sobre nuestra naturaleza. ¿No era el hombre una entidad tan susceptible de ser estudiada a través de las ciencias como las estrellas o las plantas? ¿No se podía conocer científicamente al hombre, no se podían establecer de manera científica sus necesidades y sus deseos para resolverlos científicamente? Este impulso racional, que produjo progresos notables en el mundo político y económico, dejó en evidencia un vacío. Al tratar de cubrir con las ciencias de la razón el estudio de lo humano, de repente se notó más que antes la existencia de un espacio al cual esas ciencias no alcanzaban a llegar: un espacio irracional, contradictorio y oscuro, que no se puede explorar con esas herramientas. Es el lugar de nuestros demonios, de nuestros secretos inconfesables, de nuestras emociones discordantes, ese lugar donde ocurren cosas que trastocan vidas aunque sean invisibles, ese lugar de nuestra irracionalidad y nuestras pasiones y los errores que cometemos por esas pasiones y esa irracionalidad, ese lugar que no podríamos explorar ni comprender si no contáramos con esta invención que lo ilumina y, al hacerlo, nos revela quiénes somos: esta invención que nos inventa.

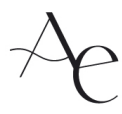

